Proceedings of the Institution of
Civil Engineers
Engineering Sustainability I59
December 2006 Issue ES4
Pages 145-154
Paper 14305
Received 22/06/2005
Accepted 24/07/2006
Keywords:
design methods \& aids/
infrastructure planning/
social impact

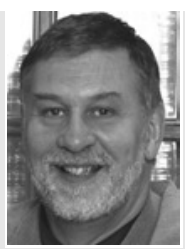

Richard Fenner Course Director, Centre fo Sustainable Development, University of Cambridge, UK

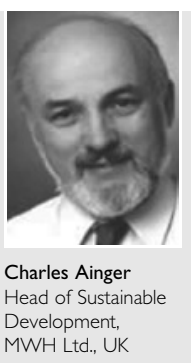

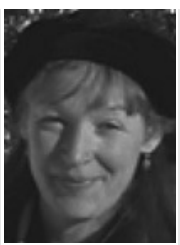

Heather Cruickshank Research Associate, Centre for Sustainable Development, University of Cambridge, UK

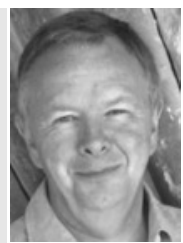

Peter Guthrie

Head, Centre for Sustainable Development, University of Cambridge, UK

\title{
Widening engineering horizons: addressing the complexity of sustainable development
}

R. A. Fenner PhD, CEng, MICE, fCIWEM, C. M. Ainger MSc, fICE, fRSA, MCIWEM, H. J. Cruickshank PhD, CEng, MICE, MCIWEM and P. M. Guthrie OBE, FREng, FICE, FCGI

The complex, fragmented and diverse aspects of a sustainable development perspective are translated into an eight-point framework that defines a problem boundary larger than that traditionally adopted by civil engineers. This leads to practical questions intended to inform engineers who ask 'am I being sustainable?' during project implementation. The value of the questions is tested against a case history of a wastewater treatment project. This demonstrates the relevance of the questions to successive project delivery phases of defining the problem, choosing a solution and implementing that solution through design, construction and operation. The case history highlights that answers to several of the additional questions raised by considering this wider problem space are currently buried within government and clients' policies, regulations and standard practice; these answers may not be accessible to the professional engineer.

\section{INTRODUCTION}

Sustainable development could become a guiding concept for engineers in the 21 st century. In the context of civil engineering, this means built infrastructure and the provision of associated services should be delivered to satisfy a broad diversity of interests and responsibilities. Engineers must continue to fulfil obligations to clients, ensure business viability and strive for excellence and robustness in the application of engineering principles. In addition, by adopting a sustainable development perspective, they must extend their role to ensuring that the real needs of all present end users are met, as well as recognising impacts (and the opportunity for mitigation and benefit) on both the natural environment and future generations.

The term 'sustainable development' is intrinsically value-laden and open to wide interpretation, with much debate about its definition. Some even see it as an emerging meta-discipline that is beginning to define a whole new subject area. ${ }^{1}$ There is a real debate about whether the complexity of current problems is so great that a reliance on technical solutions alone is unrealistic. Nevertheless, the engineer in his or her professional role will still rely on applying technical solutions to problems such as energy provision and adaptation to climate change.
To get to such solutions (civil) engineering practice needs to learn to handle a range of often unfamiliar non-technical challenges. The difficulty lies in finding ways to meet these through practical everyday engineering operations. Ideally, the sustainable development concept can be used simply to help define a wider problem boundary than those limits traditionally adopted by engineers. This then leads to the creation of a wider design space in which more holistically conceived solutions can be formulated to any given problem. ${ }^{2}$

The fundamental dilemma is the translation from a problem needing to be defined by complexity science to a solution that must be delivered by Newtonian science. This challenge may be highlighted by considering the three broad stages that a civil engineering project goes through: defining the problem; choosing a solution; and implementing it through design, construction and operation. At the outset, defining the problem requires recognition that most engineering services needed by society are framed by the whole socio-economic-environmental reality. This is a complex adaptive system, with much that is hard to measure but nevertheless vitally important, and it needs to be embraced holistically. At the other end of the process, design, construction and operation require us to use our traditional deterministic mechanics and reductionist analytical techniques. These have proved highly appropriate over the last three centuries for providing safe, working solutions, and rely completely on measurement. In between, choosing a solution requires making the transition between these two different sciences. To achieve this, more options need to be considered and evaluated, and more choice criteria developed, than are often adopted using the traditional approach. Furthermore, several of these criteria will not be conveniently measurable. Engineers will be forced to acknowledge that we need to apply values, as well as mathematics, to the trade-offs or compromises involved in the decision. These also need to be transparent and accountable to a wide constituency of interested parties.

To adopt this broader approach and then to render it down for practical implementation, this paper uses three steps. First, a sufficiently complex framework is defined. This widens both the arena in which an engineer must operate and the sphere of influence an engineer can have. Such a construct can demonstrate to non-engineer stakeholders that as responsible 
professionals we have thought holistically about the wider problem. Then, within this framework, some clearly stated questions are presented. These allow an engineer to test 'how sustainable am I being?' in terms of engineering decision-making on a real project. Such examination and scrutiny feeds directly into the overall engineering process. Finally, the framework is tested and the practicality of the questions evaluated by applying them to a case history.

\section{INCORPORATING SUSTAINABLE DEVELOPMENT}

Most past civil engineering activity has aimed at satisfying three overarching requirements: quality, cost and time (to project completion). This frequently translates into saying that economic profitability, market conditions and competition are the over-riding factors that govern 'problem space' and the choice of solutions. These criteria can be seen as defining the traditional arena in which built environment schemes are conceived and delivered.

Sustainable development is often discussed in terms of balancing the triple bottom line constraints of economic, social and environmental factors. For many this remains aspirational and vague and has recently been amplified by the UK Government ${ }^{3}$ in a strategy for sustainable development that sets out five key principles

(a) living within environmental limits

(b) ensuring a strong, healthy and just society

(c) achieving a sustainable economy

(d) promoting good governance

(e) using sound science responsibly. effectively' and 'Do things right, having decided on the right thing to do'.

There are systems already in use by the industry (such as the proprietary SPeAR Tool ${ }^{6}$ ) that help drive sustainable thinking into the design process. Other professional responses so far have included a number of high-level codes of professional conduct (e.g. Institution of Civil Engineers) and practical assessment tools and indicators (e.g. CIRIA $^{7}$ and others) for specific sectors and projects. Such devices are useful, indeed essential, but also inward looking. They do not demonstrate to the outside world that engineers have indeed thought as widely as necessary. Nor do the principles always offer sharp, practical answers for individual companies and engineers. Of equal importance is to step back and reflect on whether engineers are formulating the right questions to help critical self-appraisal of whether sustainable actions are being conceived and followed.

Jabareen $^{8}$ undertook a critical review of the vast literature dealing with sustainable development. This revealed the lack of a comprehensive theoretical approach for understanding its complexity, with often vague definitions, fragmented approaches and a lack of guidance on how the issues could be operationalised. Through the production of a knowledge map Jabareen provided a comprehensive representation of sustainable development thinking. Much of the current debate was encompassed in seven domains: ethics, fairness, urban form, preservation of natural capital, integrative management, global discourse and utopian ambition. Drawing on each of these as helpful prompts, and adding a further domain on financial management, an eight-point framework was developed (Fig. 1). It is principally conceived for civil engineers in a UK or developed
A compelling review of the many sets of principles that have been developed to both track progress towards sustainability and provide a clear direction to follow is provided by Edwards. ${ }^{4}$

In an attempt to set these elements of sustainable development in an engineering context the Royal Academy of Engineering (RAE) has recently published a set of twelve guiding principles. ${ }^{5}$ These have helped to illustrate the importance of sustainable development and what can be achieved in a practical context. Alongside the principles is a collection of case studies that demonstrate examples of sustainability issues in engineering and show that much useful good practice is already being achieved. The RAE principles offer high-level advice such as: 'Practice what you preach', 'Plan and manage

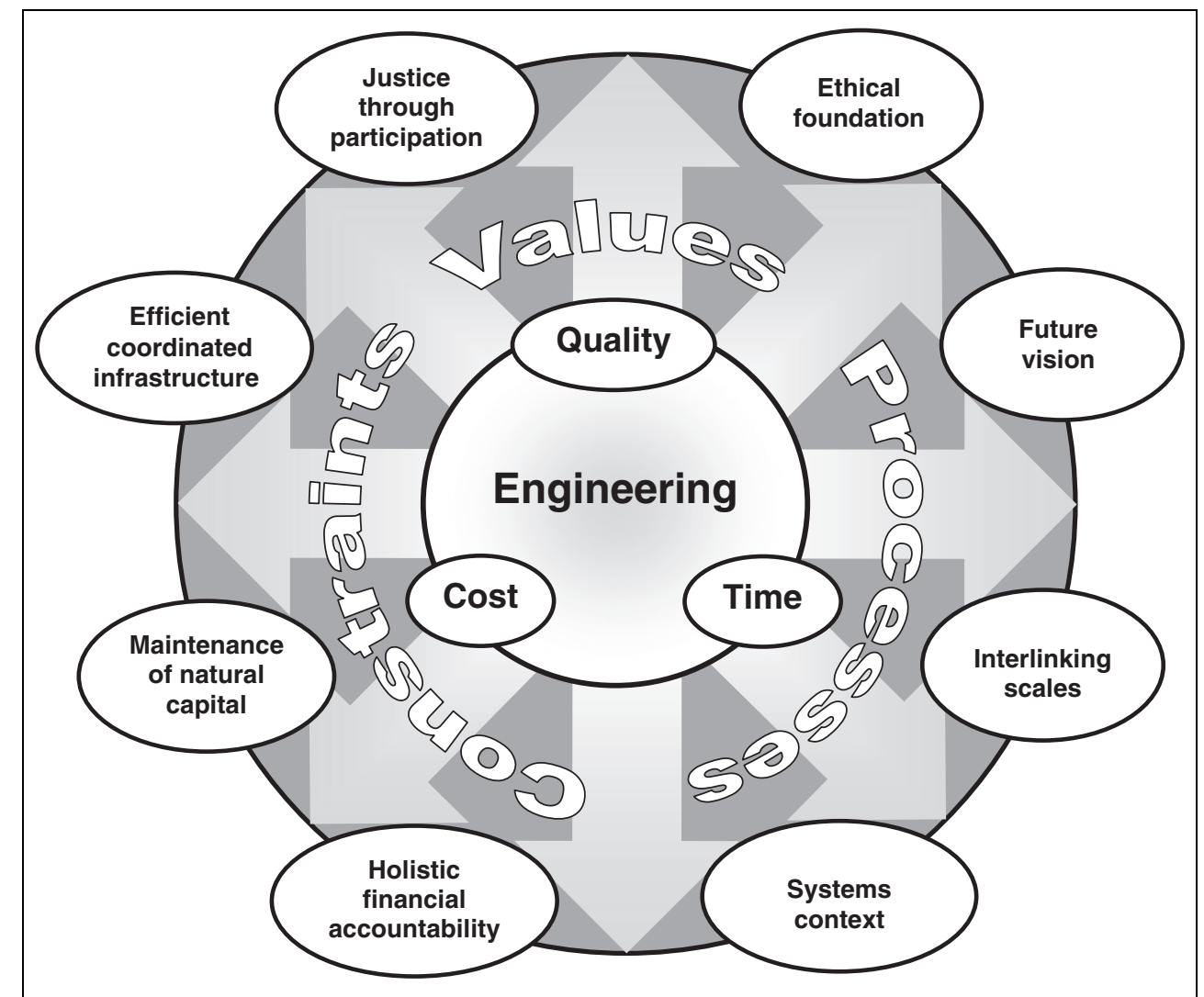

Fig. I. A sustainable framework for civil engineers 
country context, and is designed to expand the solution space in which construction and built environment professionals reach decisions by embracing values and integrative processes and acknowledging non-engineering constraints. Each point in this framework is discussed in the following sections.

\section{I. Ethical foundation}

Engineers do not operate in a vacuum but are constantly required to make value judgements. Often these judgements have not been recognised as value-based and we have acted as if they are 'objective science' even when they are not. In order to guide these judgements a system of ethics is essential. The first Engineer of the 21 st Century Inquiry ${ }^{9}$ insisted: 'Practical change in our ethics is absolutely necessary if sustainability is to be achieved-just as necessary as scientific and technological advance'. Such ethics may be framed by reference to the aims of sustainable development. The Earth Charter ${ }^{10}$ states: 'We urgently need a shared vision of basic values to provide an ethical foundation for the emerging world community' and goes on to suggest that interdependent sustainable development principles can be used 'as a common standard by which the conduct of all individuals, organisations, businesses, governments and trans-national institutions is to be guided and assessed'. The relevance of ethics to our framework is on the intellectual underpinning that an ethical foundation provides. Such rigour is important in justifying specific courses of engineering action (or avoidance).

\subsection{Justice through participation}

The areas of social equity, equal rights for development, democracy, public participation and empowerment are included in this aspect of the framework. Justice through participation calls for broad involvement and, through this, a willingness to share knowledge and achieve mutual learning. However, this concept goes beyond normal practices of stakeholder engagement and includes the notion of fairness and justice (e.g. by actively seeking a genuine two-way dialogue). In engineering terms this refers to ways of addressing the diverse and often conflicting stakeholder attitudes towards an engineering intervention. For example, fairness regarding the affordability of options for all stakeholder groups is a key concern. Such considerations often go to the heart of understanding the real needs for the engineering solutions that are being proposed and which require engineers to be scrupulous in terms of transparency and justification of decision making.

\subsection{Efficient provision and co-ordination of infrastructure}

Civil engineers consciously shape the built environment. Examples of good practice include creating infrastructure that minimises ecosystem damage, is energy and resource efficient, and contributes to healthy, vibrant and cohesive human habitats. This part of the framework therefore deals with the use of alternative building materials, minimising waste, maximising energy efficiency, and facilitating recycling and material conservation. Efficiency and co-ordination encourage engineers to work within wider land use planning constraints and adopt integrative approaches linking transportation, mixed-use development and brown field regeneration, as well as preventing unsustainable developments in areas such as flood plains and the encouragement of biodiversity in town and city landscapes, wherever possible.

\subsection{Maintenance of natural capital}

Natural capital has been defined by Pearce and Turner ${ }^{11}$ as 'the stock of all environmental and natural resource assets, from oil in the ground to the quality of soil and groundwater, from the stock of fish in the oceans to the capacity of the globe to recycle and absorb carbon'. The approach to natural capital lies at the heart of the 'weak sustainability' versus 'strong sustainability' debate, fully explored by Neumayer. ${ }^{12}$ The 'weak sustainability' view assumes that forms of capital (human, built, social, financial and natural) are completely substitutable for each other while the value of the overall capital stock must not be allowed to decline for the indefinite future. Proponents of 'strong sustainability' argue that some ecological assets such as the ozone layer or biological diversity are not substitutable, and they form "critical natural capital' the destruction of which must not be allowed as human survival depends on them. ${ }^{13}$ Engineers have developed powerful ways of altering and destroying natural capital ('for the use and convenience of man' as the traditional Tredgold definition of civil engineering reminds us*). However, natural capital cannot be created at the rate at which it is likely to be depleted by industrialising activities. Therefore in terms of ecological economics (a branch of economic theory that assumes an inherent link between the health of ecosystems and that of human beings), it should not be considered as substitutable by other forms of capital. ${ }^{15}$

Recent trends have seen increasingly tight environmental constraints being imposed on engineering activity. Indeed, the ability to mitigate environmental impacts successfully has been seen in the minds of many engineers as evidence that sustainability is being addressed and achieved. In this framework, while the widely accepted need to maintain ecosystem function and diversity is important, it is not the sole or overriding driver.

\subsection{Holistic financial accountability}

Engineers must adopt a transparency in their business practices and a willingness to accept that by-products of construction activities may affect the well-being of people or damage the environment. Those impacts should be reflected in market prices. Often the costs (or benefits) associated with externalities (e.g. the cost of natural resource depletion, pollution and other environmental and social factors) do not enter standard cost accounting schemes. The Federation of Property Societies ${ }^{16}$ has claimed that the image of construction within the public sector has been one of driving down initial capital costs, while longer term maintenance or energy costs have been 'worthy of just a passing glance at most'. The National Procurement Strategy ${ }^{17}$ stated 'in the context of a procurement process, obtaining 'best value for money' means choosing the bid that offers the optimum combination of whole life costs and benefits ... (and) not the lowest initial price option'. Therefore a whole life appraisal should undertake a systematic assessment of all relevant expenses, income and performance associated with

*'Civil engineering is the art of directing the great sources of Power in Nature for the use and Convenience of man. ${ }^{14}$ 
the acquisition, procurement, ownership and potential disposal of an asset over its life. For a building, over a 30-year period these costs can be $5-10$ times the capital cost.

\subsection{Systems context}

No single act of development can achieve its objectives in complete isolation from all other aspects. A systemic approach is required of the kind consistently advocated by Meadows et al. ${ }^{18}$ over the last four decades. In this respect problems are not dealt with in isolation but solutions are conceived against a wider understanding of the overall system response. Thus the provision of an engineered artefact or service is not divorced from the needs of its end user community. Neither are its whole life impacts ignored during the separate phases of design, implementation, operation and disposal. For example, legislative and regulatory pressure to seek incremental improvement in aquatic environments through the imposition of tighter effluent discharge standards is challenged by the wider impacts of energy consumption and greenhouse gas emissions that are created as a by-product by some of the technical solutions to the initial problem.

Efforts should be made to understand all the system components and their inter-relationships. While engineers know a lot about technical systems (in the sense that an aerospace engineer can cope with 150000 control loops in a Boeing 747), the system often stops at the technical boundary. In the context used here it represents an integrative approach to project planning and delivery.

\subsection{Interlinking scales}

A key feature when examining implications of sustainable development is one of scale. We can all view sustainability differently when viewed from the perspective of individual lifestyles, or collectively at regional, national or global levels. We may advocate advances in our transport infrastructure, but are unlikely to welcome the loss of our personal land to satisfy the construction of the latest urban motorway. Development at different spatial and temporal levels is interlinked, and engineering 'solutions' always need to take account of linkages at other scales. ${ }^{18}$ All too often the considerations of impacts arising from a construction project stop at the site boundary. This implies that secondary impacts relating to the winning of primary materials from (much) further afield and affecting environments and communities are beyond the remit of the 'local' engineer.

All decisions are taken in a boundary space that limits the responsibility of the decision makers in some way. Clearly, every decision does not have to address the global issues of climate change, global poverty, and so on. However, where the boundaries are drawn must be acknowledged as having a profound effect on the decisions taken.

With respect to temporal scales there needs to be balance between inter- and intra-generational equity, reflecting the way in which resources are allocated between current and future generations. The time dimension is a central factor here in that current engineering decisions should not restrict future living standards or choices that may be made by future generations.

\subsection{Future vision}

Much has been talked about post-industrial societies, and whether a truly sustainable society can be created. ${ }^{19}$ This is a controversial and unresolved debate. What is important is at least to possess the vision that improvements in the quality of the environment, social fairness and economic prosperity can be sought through change. This dimension equates with previous concepts such as quality and provides an overriding purpose to the provision of engineering services. This leads to a continuous need for re-invention of engineering practices and a challenging attitude to traditional procedures. These may have been conceived within a much narrower framework, suitable for their time, but no longer capable of meeting 21 st century challenges. Such changes are required of engineers as a response to the wider transformations in societal expectations of their contribution and delivery. In short, engineers need to include in their work an understanding of the implications of their actions.

Defining a desirable outcome or future is at the heart of the 'backcasting' technique. ${ }^{20}$ This has been described as: 'an attempt to envision an acceptable future system state, taking into account the status of as many important defining constraints and criteria as possible, including the requirement to meet "needs". This system state is then used as a reference for tracing pathways back to the present, for placing milestones along those pathways and for identifying short-term challenges and obstacles that will have to be overcome en route. Backcasting thus provides a way of 'connecting the future to the present'. ${ }^{21}$ The backcasting method is advocated by The Natural Step and Forum for the Future as a way of determining a route towards sustainability. ${ }^{22}$ The technique's chief virtue is helping focus on a development trajectory that avoids merely extrapolating forward from within present constraints. Meadows et al. ${ }^{18}$ believe that a sustainable world can never be fully realised until it is widely envisioned, while accepting that vision without action is useless and needs to be disciplined by scepticism. Yet vision is absolutely necessary to guide and to motivate.

\subsection{Wider horizons}

The eight key elements described above capture much of the complexity inherent in the current debate about sustainable development and can be used to set the enlarged boundary for the approach we are seeking. It is worth noting that in developing this wider boundary the term environment has consciously been avoided as sustainable development is often misconceived as solely addressing a well-developed environmental agenda. Essentially these eight elements define a wider horizon, and provide the opportunity to redefine our approach to civil engineering within a sustainable development context as follows.

(a) An ethical foundation and justice through participation lead to new values to apply when making engineering decisions.

(b) A future vision, interlinking scales, and system context provide the basis for new processes that can be used to better define problems and offer guidance in choosing appropriate strategies for development.

(c) Holistic financial accountability, maintenance of natural capital and efficient provision of co-ordinated infrastructure provide new constraints in formulating solutions. 
These are not intended to replace the traditional cost/time/ quality approach, which must be still regarded as essential ingredients in successful projects, and so they remain at the heart of our framework as shown in Fig. 1. However, in this framework the traditional engineering requirements have evolved to encompass a broader range of considerations. These are necessary to enable civil engineering to contribute effectively to sustainable development.

\section{IMPLEMENTING SUSTAINABLE DEVELOPMENT-A QUESTIONING APPROACH}

The eight-point framework proposed here is derived from the current wide-ranging debates concerning the meaning of sustainable development and provides a demonstrably comprehensive coverage of issues. ${ }^{7}$ The eight points are useful in expanding the system boundaries within which engineers must operate and function, but they also present dangers in terms of losing focus and clarity of engineering responsibilities.

To counter this we have formulated a set of guiding questions designed to enable practising engineers to be self-critical of their decisions. These are based on the authors' collective practical civil engineering experience. Such questions require answers specific to context and responses relating to the particular company and the individual. When thoroughly addressed they can be more searching and innovation-creative than higher level principles, while still being widely applicable. Such questions can then act as concise references against which engineering decisions can be judged. Translating the framework into such a context is attempted below, with each point discussed from a perspective relevant to construction professionals.

The ethical foundation links the project proponents, the policy environment that relates to the project, the people affected by the project and the professional team involved. All projects sit within a context of prevailing attitudes, and these are imperfectly reflected in government and international policy. Beyond this general level, the project promoters and owners implicitly apply their own ethical standards to the processes of conceptual design, acquisition and procurement, development and consultation, and implementation. The professional team including the engineers occupy many positions in the evolution of a scheme. These positions are reflected by government and regulatory bodies, as well as by the client (influenced by the sources of finance), and by affected stakeholders and the professional team serving the client. One of the most difficult challenges is to determine the extent to which an individual professional should allow personal ethical standards to be subsumed by corporate behaviour and decisions, and to determine at what point the individual's position becomes untenable. In many cases the individual is not in command of sufficient information to be able to be certain about the ethical position that is being adopted. The existence of clearly articulated ethical standards in an organisation allows individuals to establish their personal attitude to challenges in a general sense. When a particular situation arises, this makes the decision more easily reached. The questions listed in Table 1 should be asked at the outset of a project.

The existence of many routes for the representation of people affected can lead to the supposition that merely to follow the rules of stakeholder engagement is to meet the requirement of justice through participation. This may not be true as there may be people who are unrepresented. There also may be over-representation of people who have the time and resources at their disposal to devote large amounts of time to fighting for a particular position. It is a reasonable duty of the engineer to seek to consider the interests of those not well represented or not represented at all, and to address the issue of 'hearing the silent'.

The social implications of development should be considered at the design stage. However, what is regarded as beneficial is a very difficult issue and very much depends on the particular state and priorities of all involved. It is necessary to consider the benefits for the key recipients as well as ensuring that the effects are not over-damaging for the rest, and to consider disparate groups separately. Practical questions that deal with this are listed in Table 2.

The provision of infrastructure in the form of transport systems, water and communication networks, flood defences, buildings and other aspects of urban fabric is an essential requirement for modern societies. These engineering services impact on the lives of all who live in towns and cities, sometimes with negative consequences (traffic congestion, pollution, noise, visual impact and wider system failures). Resources are consumed and waste and pollution are created in their construction and operation. Much planning advice is available to guide developments. Basic questions that should be considered at master planning stage and in subsequent construction scheduling are proposed in Table 3.

\begin{tabular}{|ll|}
\hline Stage of project delivery & Ethical foundation \\
\hline Defining the & - How does the engineering project meet clearly defined needs of all project proponents and end users? \\
problem (scope) & - When was the justification for the scheme or project explored? Has the way in which it fits within the \\
& - Wrevailing government policy array been established? \\
& - Where and with whom do the benefits of the scheme lie? Who wins and who loses? \\
- In the absence of certainty and with incomplete information, are value judgements based on the \\
- Precautionary principle? \\
- with corrupt or dishonourable work? \\
- How has technical advocacy for pre-determined solutions been avoided? \\
- How do the drivers for the project match our ethics and values?
\end{tabular}




\begin{tabular}{ll} 
Stage of project delivery & Justice through participation \\
\hline Defining the & - How has a fair foundation for this scheme been developed with the stakeholders? \\
problem (scope) & - Which cultural, religious, ethnic or gender issues may be relevant? \\
Choosing a solution & - Have genuine concerns been considered with an openness and willingness to adapt and modify designs? \\
Implementation & - How have the interests of those not well represented or not represented at all been recognised \\
- Wh embraced? & - What channels have been established for good communication with the public, employees and other \\
professional groups? Is the basis of decision making established and known to all likely stakeholders at \\
the outset? \\
- With whom has the extent to which participation can and will affect decisions been determined and agreed? \\
- Who carries responsibility for explaining what cannot be altered, and why? \\
- Who is involved in establishing a base of agreed positions (facts as well as aspirations)?
\end{tabular}

Table 2. Questions to establish justice is addressed for all stakeholder groups

\begin{tabular}{|ll}
\hline Stage of project delivery & Efficient healthy infrastructures \\
\hline Choosing a solution & - What opportunities for environmental enhancement (as well as mitigation) have been sought? \\
Implementation & - Are adverse impacts only accepted reluctantly? \\
- At what stage is an appropriate balance between form and function of engineered systems explored \\
- What flexible and adaptable designs have been developed to allow for extended useful life? \\
- How much flexibility of operation can be permitted to allow for future change? \\
- To what extent do designs contribute to social cohesion and inclusion, and human wellbeing and welfare? \\
- General community? \\
- What safeguards ensure the performance of the scheme is taken into account over ALL its stages, including \\
- Have plans and proposals been prepared that reflect the true position and not an idealised one? \\
- Have is the welfare of the workforce ensured and who has responsibility for highlighting safety issues? \\
- Has the 'envelope' of constraints been set around an acceptable solution? \\
- How do choice criteria required to evaluate decisions reflect sustainability issues?
\end{tabular}

Table 3. Questions to ensure efficient infrastructures provide healthy urban environments

By adopting an inventory approach that identifies the natural capital associated with (and affected by) a scheme, it is possible to enhance the performance of the project in terms of loss and gain of ecosystem function, biodiversity and resource management. Such an approach would give some weight to a design for energy efficiency, for example, and underpin a design that used maximum renewable energy and minimal fossil fuel. Such approaches also reduce the vulnerability of a scheme to future shocks of sharp increases in the costs of non-renewable sources of power and raw materials. Some helpful questions are suggested in Table 4.
A holistic approach in the financial aspects of a scheme requires that the narrow and internal interests of individual parties are at least viewed in the light of the wider project interests and wider community needs. The development of explicit corporate social responsibility objectives allows companies to identify ways in which such wider aspects can be considered. The form of agreement and contract between parties can unintentionally induce inefficiencies in a system because the wider implications are not considered. The relationships between the contracting parties can be reviewed to see if the overall aims of the project could still be achieved through modest changes in the forms of

\begin{tabular}{ll} 
Stage of project delivery & Maintaining natural capital \\
\hline Choosing a solution & - How is resource and energy efficiency optimised over the whole life of the project? \\
Implementation & - What steps are actively taken to minimise pollution arisings and negative visual impact? \\
- How is careful and informed material selection ensured and over-specification avoided? \\
- What opportunities are sought for re-use (e.g. of land, materials and building stock)? \\
- To what extent is any natural capital lost as an integral part of the scheme sought to be replaced \\
- Whd replenished? \\
change) and smaller reversible ones (recognising not all impacts carry the same weight or significance)?
\end{tabular}

Table 4. Questions to preserve natural capital 
agreement. The establishment of long-term partnership agreements has been an example of developing trust between organisations who work repeatedly together. Table 5 suggests some questions to test how environmental and social externalities are being recognised and acknowledged in accounting and reporting procedures.

The linear approach to procure, design, build, operate, (decommission) can lead to a failure to recognise the wider context in which engineering takes place as part of a series of complex systems with feedback loops involving society and the environment. Recognising wider system boundaries is a means of expanding the design space for engineering solutions and avoids ignoring the possibility of merely translating a given problem into a more remote state and others' responsibility. Appropriate questions to be asked at this stage are listed in Table 6.

Both inter- and intra-generational interests should be addressed. There is currently no explicit way of representing the interests of future generations and yet it is a cornerstone of the principle of sustainable development. It is the duty of the engineer to address the aspects of the scheme that affect future generations and to seek to develop designs and strategies that meet their needs in anticipation. More obviously, but no more easily, the interests of the current generation must be met to comply with the principle of sustainable development. The extent to which a single project of whatever scale should address inequity outside the boundaries of the scheme is contentious. Most schemes cannot be expected to consider global or even national deprivation as a part of the scheme development. Nevertheless, every scheme should be aware of the local issue of equity (e.g. how does this scheme affect the neighbouring community, the near neighbours, those in the supply chain and the people displaced and perhaps disaffected by the proposals?).

Difficulty arises when setting the boundary of a project and the questions of who benefits and how far its influence is felt must be considered. Does the benefit need to be felt by all stakeholders or do some have to sacrifice for the benefit of others? We can also ask how much sacrifice for the greater good should the individual be expected to tolerate. The effects should be considered beyond the recipient community into the wider regional or global population. The effects of pollution or use of materials can indeed have worldwide influence, and we must carefully decide on the boundaries for the scope and extent of an assessment. Some suggested questions are presented in Table 7.

Historic projects demonstrate the capacity for the long-term impact of many engineering projects. While attempting to consider future contexts and set out desirable future visions can be difficult to achieve with any accuracy, it is still a worthwhile endeavour. The consequences of many projects from the last 100 years could have been improved with a more rigorous approach that addressed the possible outcomes and scenarios and then sought to design for flexible responses to these. Many techniques are available and their exploration is likely only to enhance the design through more thorough consideration of the issues. Key questions are: does the development allow for future development possibilities and in what ways are future developments constrained? Sustainable development should allow future generations to meet their own needs in the way they see fit. One project should avoid blighting others as far as is reasonably practical. This is difficult to incorporate, however, because it requires foresight of the developments that will be required in future. Table 8 proposes questions to test how future concerns may be incorporated into current thinking.

\begin{tabular}{|ll|}
\hline Stage of project delivery & Holistic financial accountability \\
\hline Choosing a solution & - To what extent are transparent business practices audited externally and how is risk managed? \\
- How do costs reflect environmental and social externalities and at what intervals are these embraced and \\
- Weported? \\
- What methods are used to assign other than monetary value to natural assets and social gain (by scoring \\
- How are costs external to the scheme included in consideration of alternatives? \\
- What steps are taken to seek long-term relationships with clients and suppliers? \\
- Hre costs minimised only where all costs over whole life are included?
\end{tabular}

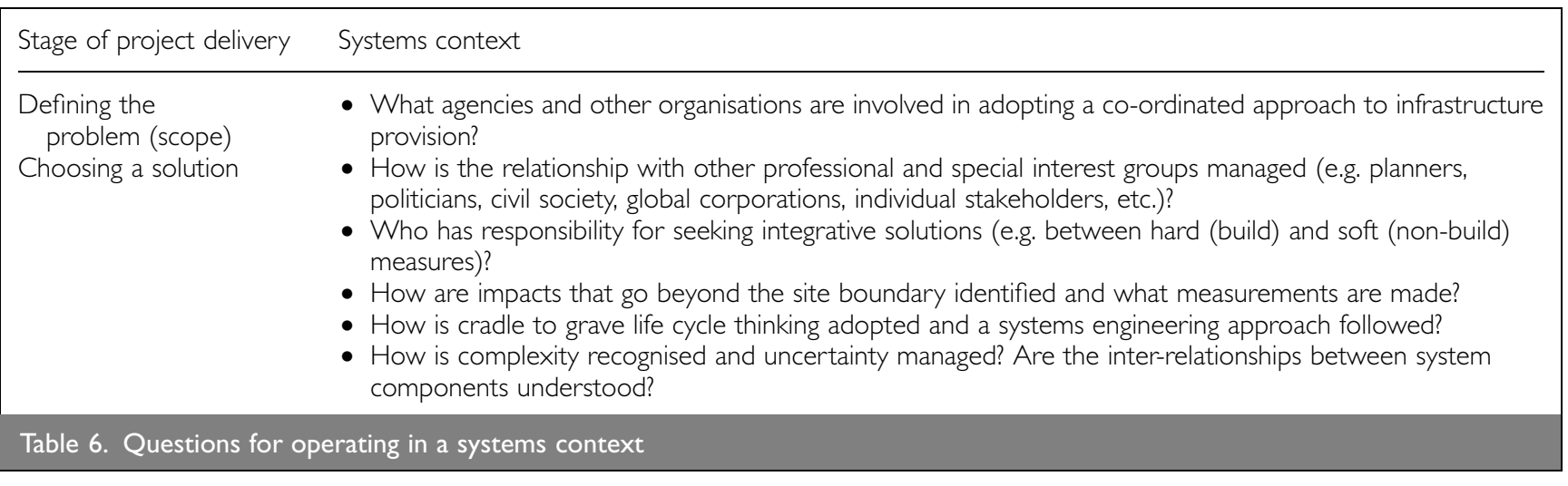




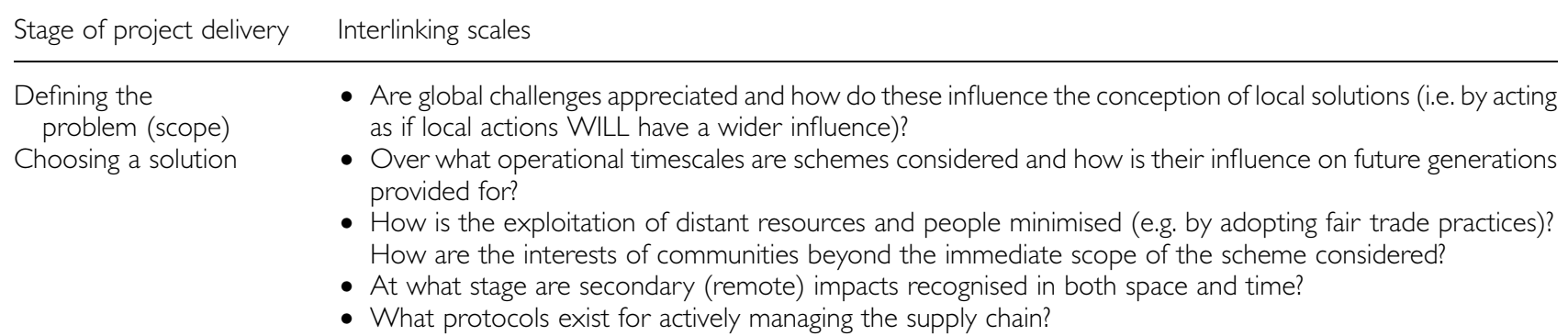

Defining the

problem (scope)

Choosing a solution

- Are global challenges appreciated and how do these influence the conception of local solutions (i.e. by acting as if local actions WILL have a wider influence)?

- Over what operational timescales are schemes considered and how is their influence on future generations provided for?

- How is the exploitation of distant resources and people minimised (e.g. by adopting fair trade practices)? How are the interests of communities beyond the immediate scope of the scheme considered?

- At what stage are secondary (remote) impacts recognised in both space and time?

- What protocols exist for actively managing the supply chain?

Table 7. Questions for assessing impacts at a range of scales

\begin{tabular}{|c|c|}
\hline Stage of project delivery & Future vision \\
\hline $\begin{array}{l}\text { Defining the problem } \\
\text { (scope) } \\
\text { Choosing a solution } \\
\text { Implementation }\end{array}$ & $\begin{array}{l}\text { - How commonplace is it to take action BEFORE legislation and regulation requires change? } \\
\text { - What assumptions are made regarding increasing levels of regulatory control over emissions, waste, natural } \\
\text { - How are methods such as scenario planning used to explore a range of futures and to ensure real needs are } \\
\text { - served through careful problem formulation? } \\
\text { - What ambitious goals and targets are set that stimulate creativity and allow innovation? How regularly are } \\
\text { - Which long-term aims are considered as important drivers as responding to today's immediate problems? } \\
\text { - How is performance benchmarked as a precursor to seeking continual improvement? } \\
\text { - What formal requirements are there to analyse past performance and learn and capture (tacit) experience? } \\
\text { - What mechanisms are used to encourage creativity and innovation? }\end{array}$ \\
\hline
\end{tabular}

Table 8. Questions for ensuring desirable future outcomes are addressed in the formulation of present day solutions

\section{APPLYING THE QUESTIONS: A PRACTICAL EXAMPLE}

The questions detailed in Tables 1-8 are being tested against a number of engineering projects and refined accordingly. The purpose is to examine the extent to which solution choices and design details would change if these wider issues were comprehensively addressed. This will be the subject of a subsequent paper, but the process has been revealing and is exemplified by the short case study summarised below.

\section{I. Case study: provision of wastewater treatment for a small rural community}

This project was driven by the need to upgrade pollution control for a small wastewater treatment works to meet the EU Urban Wastewater Directive. A shortlist of six treatment options was evaluated against a hybrid set of indicators derived collectively by the regulator, the engineers and the client from three criteria sets relevant to the key stakeholders. ${ }^{23-25}$ Each option was evaluated and ranked according to these criteria using an options-criteria matrix. This led to the recommendation of treating the wastewater locally in a two-stage lagoon system and discharging to a local stream. The solution used less materials and energy than the alternatives, provided ease of operation and no regular sludge and screenings removal, as well as allowing rapid, less complex and critical construction. Moreover, the components specified were long life and low maintenance, and allowed for the use of wind power on site.

In auditing the project against the above set of questions it was found that most had been addressed, although not necessarily through formally prompted procedures. In exploring the ethical foundation, the project is driven by EU, UK government water policy and OFWAT (the UK water regulator) decisions about what is needed and affordable. (Such decisions may not be sustainable if they simply drive changing the form of pollution from one phase to another.) The benefits notionally lie with water company customers (who may not notice or expressly desire the changes), although some households may lose by paying more and potentially suffer extra traffic, odour, visual impact or noise. Although care was taken to widen the social and environmental criteria, these were chosen and inserted by professionals and not developed through wider stakeholder consultation. In this case the ethical choice relates to whether or not the engineer agrees with the basis for the EU regulations that drive the need for the project. An explicit ethical dimension would have added rigour to hold the client to a sustainability approach, had he been inclined to challenge it.

Justice through participation generically resolves into one key question: have the extent and rules of stakeholder dialogue been transparently established? In this project the need to protect the interests of those not represented in the process was not fully explored, and the process of managing disagreement was not discussed beyond working within the consensus of the 'professional' group. The unproven assumption here is that the radical solution adopted would have been what the stakeholders wanted, but this was not tested. The systemic problem of the relative importance of the opinions of one stakeholder or group of stakeholders was also not resolved here, and remains a challenge in almost all developments.

The questions for delivering efficient infrastructure are reflected in this case by the wide number of alternative options examined, although no specific enhancement features were considered. Wider integration was also not achieved as the EU regulations simply seek to solve a narrow water pollution related problem. Extending the problem space might have led to greater emphasis 
on excluding rainwater at source and local industrial on-site waste treatment, and integration with other local waste management. With regard to social criteria, issues such as local wealth creation opportunities or long-term employment were not considered.

Emphasis on maintaining natural capital was addressed and covered through the option selection criteria, although weightings for comparing different impacts were not defined. The chosen solution converted agricultural land to a "natural process' treatment system, and responding to the questions may have added more incentive to providing more sensitive landscaping. No explicit quantification of the natural capital lost by adopting the preferred solutions was made, which could have led to 'replacement' proposals being formulated. A formal environmental management system was applied to the construction and operation phases of the project.

With regard to transparent financial accountability, the choice criteria and final evaluation through the decision matrix included environmental and social criteria and allowed trade-offs between cost and other factors to be seen. However, there was no specific inclusion of costed externalities, but the decision went far beyond mere reliance on a straightforward cost/benefit analysis only.

Within a wider systems context there was an attempt to re-consider project boundaries and scope of measurements, such as wider (non-local) discharge points and climate impacts. Practical difficulties arise because some impacts may not be easily measurable. Many aspects of the questions under the interlinking scales and future vision nodes were not explicitly considered, despite the project being conceived and developed against the principle of achieving sustainable development. If these aspects had been addressed, it seems likely they would have reinforced the case for the preferred low-energy localised process solution that was actually selected. However, the recommendation of reducing phosphorous at source might also have been a logical outcome.

\section{CONCLUSIONS}

Applying the framework and associated questions set out in this paper could lead to more formal sustainability assessment processes at relevant stages of project delivery, for example in scoping both the project and the engineers' role with the client, in discussing the validity of (and even challenging) the project drivers, and in agreeing the extent of social and environmental engagement as well as through defining the values the client will use in decision making. Other practical steps to emerge from this analysis are the need to establish transparently and formally the extent and rules of stakeholder consultation, and deliberately to extend the range of options examined. The emphasis is on asking more searching questions at both the problem and solutions stages, so both the constraints and choice/ evaluation criteria are stretched, as achieved in the case study examined above.

We suggest that the questions derived from this holistic framework are practical and useful and can help drive more sustainable projects provided they are discussed early and built into the standard processes for project delivery, not left to be added as 'extras' later on. Moreover, many of the concerns raised reflect the objectives that leading clients are already adopting and reporting on. However, if the example of the case history is general (it comes from an EU Directive dominated sector), then answers to these questions may often be buried within government and clients' policies, regulations and standard practice, not regularly addressed by them, and not accessible to engineers actually delivering the project.

If it were possible to agree and standardise on such questions, possibly in an appropriate way for each sector, then answers could be given by the relevant party at the right stage from the project outset and accumulated in a standard 'sustainability ethics' annex that could be attached to each project information record. Reference to this would allow an engineer at any stage to answer the most important question: 'how have we addressed sustainability on this project?'.

Finally, answering such questions will help drive demand for long-term improvements in the sustainability literacy of engineers. The nature of the required changes to traditional academic engineering courses has been described elsewhere. ${ }^{2}$ It is an essential requirement that engineers possess a rigorous understanding of the physical and mathematical principles through which their designs will function, but engineering design is only part of a spectrum of skills needed in the delivery of projects, products and services. Engineering is affected by, and affects, other issues that are not so easily defined. This requires dealing with complex non-technical details and future engineers must have an understanding of the qualitative as well as the quantitative aspects of their practice.

\section{REFERENCES}

1. Mihelcic J., Crittenden J., Small M., Shonnard D., Hokanson D., Zhang Q., Chen H., Sorby S., James V., SutherLAND J. and SchNoor J. Sustainability science and engineering: the emergence of a new meta-discipline. Environmental Science \&t Technology, 2003, 37, No. 23, 5314-5324.

2. Fenner R. A., Ainger C., Cruickshank H. J. and Guthrie P. Embedding sustainable development at Cambridge University Engineering Department. International Journal of Sustainability in Higher Education, 2005, 6, No. 3, 229-241.

3. UK Government. Securing the Future-UK Government Sustainable Development Strategy. The Stationary Office, London, 2005.

4. EdWARDS R. A. The Sustainability Revolution-Portrait of a Paradigm Shift. New Society Publishers, Gabriola Island, Canada, 2005.

5. Dodds R. and Venables R. Engineering for Sustainable Development: Guiding Principles. Royal Academy of Engineering, London, 2005.

6. ARUP. SPeAR Product Overview. See http://www.arup.com/ environment/feature.cfm?pageid=1685 for further details.

7. WS AtKins Consultants. Sustainable Construction: Company Indicators. CIRIA, London, 2004, Report C 701CD.

8. JABAREEN Y. A knowledge map for describing variegated and conflict domains of sustainable development. Journal of Environmental Planning and Management, 2004, 47, No. 4, 623-642. 
9. Forum For THE Future. The Engineer of the 21st Century Inquiry-Engineers for Sustainability. See http:// www.forumforthefuture.org.uk/ for further details.

10. United Nations Earth Charter Commission. The Earth Charter. Report to the General Secretary of the United Nations, approved at UNESCO Offices, Paris, 2000.

11. Pearce D. and Turner R. K. Economics of Natural Resources and the Environment. Johns Hopkins University Press, Baltimore, Maryland, 1990.

12. Neumayer E. Weak Versus Strong Sustainability, 2nd edn. Edward Elgar, Cheltenham, 2003.

13. PeRdAn S. Introduction to sustainable development. In Sustainable Development in Practice (AzAPAgIC A., Perdan S. and Clift R. (eds)). Wiley, New York, 2004, p. 25.

14. TREDGold T. Extract from the Charter of the Institution of Civil Engineers. Updated version available at www.ice.org.uk/icextra/icextra_council.asp.

15. United Nations Millennium Project. Millennium Ecosystem Assessment Synthesis Report. A report to the United Nations Secretary General, 2005.

16. Federation of Property Societies. Whole Life Appraisal. See http://www.ipf.co.uk/AssetManagement/AMPNetwork/ fps/wla.pdf for further details.

17. Office of the Deputy Prime Minister. National Procurement Strategy for Local Government. ODPM, Wetherby, 2003.
18. Meadows D., Meadows D. and Randers J. Limits to GrowthThe 30-year Update. Chelsea Green Publishing, Vermont, 2004.

19. BAteson P. Can affluent people adapt to a world of sustainable development? In Towards Sustainable Consumption: A European Perspective (HEAP B. and Kent J. (eds)). Royal Society, London, 2000.

20. Dreborg K. H. Essence of backcasting. Futures, 1996, 28, No. 9, 813-828.

21. Weaver P., Jansen L., Van Grootveld G., van Spiegel E. and Vergragt P. Sustainable Technology Development. Greenleaf, Sheffield, 2000.

22. Holmberg J. Backcasting: a natural step in operationalising sustainable development. Greener Management International, 1998, 23, Autumn, 30-51.

23. The LAND Is Ours. Defining Rural Sustainability: Fifteen Criteria for Sustainable Development in the Countryside together with Three Model Policies for Local Plans. Report by The Planning Office of The Land Is Ours group, 1999.

24. Wilson S., Bray R. and CoOper, P. Sustainable Drainage Systems: Hydraulic, Structural and Water Quality Advice. CIRIA, London, 2004, Report C609.

25. WATER UK. Towards Sustainability 2003-2004 (UK Water Industry) Sustainability Indicators 2003/2004. Water UK, London, 2005.

\footnotetext{
What do you think?

To comment on this paper, please email up to 500 words to the editor at journals@ice.org.uk

Proceedings journals rely entirely on contributions sent in by civil engineers and related professionals, academics and students. Papers should be 2000-5000 words long, with adequate illustrations and references. Please visit www.thomastelford.com/journals for author guidelines and further details.
} 